\title{
Submandibular Bez Cerrahi Sonuçlarımız
}

\section{Submandibular Gland Surgery: Our Experience Aytuğ BUYRUK ${ }^{1}{ }^{(}$, Ferhat BOZKUŞ 1}

Öz.

Amaç: Kliniğimizde submandibüler bez eksizyonu yapılan hastalara ait, semptom, demografik özellikler, klinik ve radyolojik tanı yöntemleri, cerrahi spesimen histopatolojik bulguları, cerrahi komplikasyonlar ve izlem bilgilerinin paylaşıımasıdır.Cerrahi sonuçlarımızın ve komplikasyonlarımızın literatürle karşılaştırıarak eksiklerimizi gidermek komplikasyon oranlarımızı düşürmek için yapabileceklerimizi araştırmak,hastaya daha iyi cerrahi sağlamak için yurtiçi ve yurtdışı yapılan uygulamaları araştırmaktır.

Materyal ve Metot: Bu çalışma, 2005-2019 yılları arasında üçüncü basamak bir hastane olan Harran Araştırma ve Uygulama hastanesi Kulak-Burun-Boğaz kliniğinde submandibular bez eksizyonu yapıımış olan 45 hastaya ait dosya bilgileri kullanılarak geriye dönük olarak düzenlendi. Kliniğimizde submandibülar bez eksizyonu yapılan hastalara ait, semptom, demografik özellikler, klinik ve radyolojik tanı yöntemleri, cerrahi spesmen histopatolojik bulguları ve cerrahi komplikasyonlar hasta dosyalarından geriye dönük olarak taranarak elde edildi.

Bulgular: Hastaların 30'u $(\% 66,6)$ ağrılı şişlik,15'i $(\% 33,3)$ ağrısız şişlik şikâyeti ile başvurmuştur. Cerrahi spesimenin histopatolojik incelenmesinde 20 hastada $(\% 44,5)$ kronik sialadenit 13 hastada $(\% 28,9)$ sialolitiazis, 5 hastada (\%11) benign tümörler, 2 hastada $(\% 4,5)$ malign tümörler, 4 hastada kazeifiye granülomatöz hastalık $(\% 8,9) 1$ hastada ranula $(\% 2,2)$ saptanmıştır. Komplikasyonlar 2 hastada $(\% 4,5)$ fasial sinir marjinal mandibüler dalına ait kalıcı paralizi, 1 hastada lingual sinir paralizisi $(\% 2,2)$, bir hastada da ise yara yeri enfeksiyonu $(\% 2,2)$ görüldü.

Sonuç: Submandibuler bezde kitle şikâyeti ile başvuran hastalarda tanı çoğunlukla kronik sialadenit ve sialolitiazis olmuştur. Trans servikal submandibuler bez eksizyonu,cerrahi tekniklere uyulduğunda ve seçilmiş hastalara uygulandığında, düşük komplikasyon ve nüks oranlarıyla yüz güldürücüdür.

Anahtar Kelimeler: Submandibular bez, Cerrahi, Komplikasyonlar

\section{Abstract}

Background: Symptoms, demographic characteristics, clinical and radiological diagnostic methods, histopathologic findings of surgical specimens, surgical complications and follow-up information of patients who underwent submandibular gland excision in our clinic. The aim of this study is to compare the results of our surgical results and complications with literature and to find out what we can do to reduce our complication rates and to investigate the domestic and international practice in order to provide better surgery to the patient.

Materials and Methods: This study was performed retrospectively by using file information of 45 patients between 2005-2019 who had undergone submandibular gland excision at Harran Research and Training Hospital Ear-Nose-Throat Clinic. Symptoms, demographic characteristics, clinical and radiological diagnostic methods, surgical specimen histopathologic findings and surgical complications of patients who underwent submandibular gland excision were obtained retrospectively from the patient files.

Results: Thirty patients (66.6\%) presented with painful swelling and 15 patients $(33.3 \%)$ presented with painless swelling. Histopathological examination of the surgical specimen revealed chronic sialadenitis in 20 patients (44.5\%), sialolithiasis in 13 patients (28.9\%), benign tumors in 5 patients (11\%), malignant tumors in 2 patients (4.5\%), caseified granulomatous disease in 4 patients (8.9\%) 8) and ranula (2.2\%) was detected in 1 patient. Marginal mandibular nerve paralysis in 2 patients (4.5\%), lingual nerve paralysis in one patient (2.2\%), infection in one patient (2.2\%)

Conclusions: In patients presenting with mass complaints in the submandibular gland, the diagnosis was mostly chronic sialadenitis and sialolithiasis. Trans cervical submandibular gland excision is satisfactory with low complication and recurrence rates when surgical techniques are followed and applied to selected patients.

Key words: Submandibular gland, Surgery, Complications

\section{Sorumlu Yazar I Corresponding Author}

Dr. Aytuğ BUYRUK

Harran Üniversitesi Tıp Fakültesi, Kulak-Burun-Boğaz AD Şanlıurfa

Şanlıurfa-Mardin Karayolu üzeri 22. Km Osmanbey kampüsü

Şanlıurfa/Türkiye 63050

Telefon: 0 (414) 3183031

Faks: 0 (414) 3183192

e-mail: aytugbuyruk@hotmail.com

Geliş tarihi / Received:

27.11.2019

Kabul tarihi / Accepted:

21.02.2020

DOI: 10.35440/hutfd.651611 


\section{Giriş}

Submandibülar bezin primer kitleleri parotis kitlelerine nazaran oldukça nadir görülür. Dolayısı ile bu beze yönelik cerrahilerin önemli bir kısmında sebep tükürük bezinde taş ve genellikle taşa ikincil gelişen tükürük bezi kronik enfeksiyonlarıdır. Otopsi çalışmalarında sialolitiazis insidansı \%1 olarak rapor edilmekle birlikte,klinik olarak semptomatik taşlar çok daha nadirdir. Semptomatik taş olgularının \%80-92'si submandibüler bez kaynaklıdır (1). Taşın sebep olduğu kronik obstrüksiyon submandibular bezde palpasyonda kitle hissi veren submandibular bezde sertlikle karakterize kronik inflamasyona sebep olabilir. Genellikle asemptomatik olan bu hastalarda herhangi bir tedavi gerekmeyebilir fakat sık tekrarlayan akut inflamasyon ve özellikle yemek sonrası submandibular bölgede şişlik ve ağrı, submandibular bez eksizyonunu zorunlu kılar. Submandibular bez eksizyonu, siyalolithiasis, kronik siyaloadenit ve tümör gibi submandibular bezin birçok hastalı̆ının tedavi şeklidir (2). Tüm baş boyun tümörlerinin \%3'ü tükürük bezlerinde görülür. Bunların \%70-80'i parotis bezinde, \%10'u submandibular bezde, \%1'i minör tükürük bezlerinde görülür $(3,4)$. Submandibular bezde görülenlerin yaklaşık \%50'si maligndir. Submandibular bez malign tümörleri için de en sık adenokistik karsinomaya rastlanmaktadır (3). Benign tümör olarak ise submandibular bezde aynı parotis bezinde olduğu gibi en sık pleomorfik adenoma rastlanmaktadır $(5,6)$. Trans servikal submandibülar bez eksizyonu kronik sialadenit,sialolitiazis, benign ya da malign bez tümörlerinde tanı yada tedavi amaçlı uzun yıllardır kullanılmaktadır. Fakat literatürde, submandibüler bez eksizyonu ile ilgili uzun dönem geniş olgu serisi bildirimi kısıtı sayıda mevcuttur (7). Bu çalışma kliniğimizde yapılan cerrahileri bilim camiasıyla paylaşmak bu sırada literatürde ülkemizde ve yurtdışında submandibular cerrahi ile ilgili güncel yaklaşımları takip etmek ve katkı sunmak açısından önem arz etmektedir.

\section{Materyal ve Metod}

Bu çalışma, 2005-2019 yılları arasında üçüncü basamak bir hastane olan Harran Araştırma ve Uygulama hastanesi Kulak-Burun-Boğaz kliniğinde submandibular bez eksizyonu yapılmış olan 45 hastaya ait dosya bilgileri kullanılarak geriye dönük olarak düzenlendi. Kliniğimizde submandibular bez eksizyonu yapılan hastalara ait semptom, demografik özellikler, klinik ve radyolojik tanı yöntemleri, cerrahi spesmen histo-patolojik bulguları ve cerrahi komplikasyonlar hasta dosyalarından geriye dönük olarak taranarak elde edildi.Veriler SPSS versiyon 20'ye aktarılarak program frekans, yüzdelik dilimler, ortanca, ortalama ve standart sapmaları hesaplamak için kullanıldı.Ayrıca cinsiyet, yaş,tümör tarafı arasında anlamlı fark olup olmadığı kikare testiyle analiz edildi. Çalışma yerel etik kurul tarafından onaylanmış ve 28/08/2019 tarih, E.35566 sayııı izni ile yürütülmüştür.

\section{Bulgular}

Çalışmada 46 hastanın dosyası tarandı fakat bir hastanın patolojisinin submandibular bezden kaynaklanmadığı (submandibular bölge lipomu) anlaşılarak çalışma dışı bırakılmışıı.26 erkek,19 kadın olmak üzere 45 hasta çalışmaya dahil edilmiştir. Ortalama yaş 36.2(10-72) idi. Hastaların 23'ünde (\%51.1) sol, 22'sinde (\%48.9) sağ submandibülar tükürük bezi eksizyonu yapıldı. Hastaların 30'u (\%66.6) ağrıı şişlik, 15'i (\%33.3) ağrısız şişlik şikayeti ile başvurdu. Submandibülar üçgenin fizik muayene bulgularına göre hastaların $15^{\prime}$ inde (\%33.3) ele gelen kitle, 20 'sinde (\%44.5) palpasyonda bez üzerinde ağrı-hassasiyet, 6 'sında (\%13.3) sert bez, 4 'ünde (\%8.9) ele gelen taş mevcuttu (Tablo 1).

Tablo 1. Hastaların Demografik Özellikleri

\begin{tabular}{l|l|ll}
\hline \multicolumn{2}{c}{ Sayı } & $\%$ \\
\hline Cinsiyet & Erkek & 26 & 57.8 \\
& Kadın & 19 & 42.2 \\
& & & \\
Ortalama yaş & Erkek & 37.3 & \\
& Kadın & 34.6 & \\
Taraf & Sağ & 22 & 48.9 \\
& Sol & 23 & 51.1 \\
Bulgular & Ağrılı submandibular bez & 20 & 44.5 \\
& Sert submandibular bez & 15 & 33.3 \\
& Ele gelen kitle & 6 & 13.3 \\
& Ele gelen taş & 4 & 8.9 \\
& Marjinal mandibular sinir paralizisi & 2 & 4.5 \\
Komplikasyon & Lingual sinir paralizisi & 1 & 2.2 \\
& Enfeksiyon & 1 & 2.2 \\
\hline
\end{tabular}

Tanı yöntemi olarak en sık ultrasonografi (USG) 29 hastada (\%64.4) tercih edildi. Ayrıca 23 hastada (\%51.1) bilgisayarlı tomografi (BT), 18 hastada (\%40) manyetik rezonans görüntüleme (MRG) tercih edildi. 13 hastada hem USG hem BT,11 hastada hem USG hem MRG,iki hastada hem BT hem MRG,bir hastada da her üç tetkik de istenmiştir. Ağrısız şişlik şikayeti ile başvuran ve preoperatif değerlendirmede tümör düşünülen ayrıca yapılan görüntüleme tetkiklerinde histopatolojik korelasyon önerilen 11 hastaya (\%24.4) ince iğne aspirasyon biyopsisi (iIAB) yapilırken, bunlardan 9 hastada benign sitolojik bulgular lehine rapor edildi, bir hastada benign sitolojik bulgular lehine raporlanan ince iğne sonucu submandibular bez eksizyonu sonucu non-hodgkinlenfoma olarak raporlandı, 1 hastada da ince iğne sonucu tanısal değil olarak raporlandı.

En sık görülen benign tümör \%8.9 ile (4 hasta) pleomorfik adenomdu (Şekil 1, Şekil 2) 1 hastada da lenfoepitelyal lezyon görüldü. Malign tümörü olan iki hastanın tanıları lenfoma ve adenoid kistik karsinoma idi. (Tablo 2).Ayrıca bir hasta ranula ve dört hasta kazeifiye granülomatöz lezyon 
olarak raporlandı

Tablo 2. Hastaların Histopatolojik Tanıları

\begin{tabular}{lccc}
\hline Histopatoloji & Hasta Sayısı & Ortalama Yaş & $\%$ \\
\hline Kronik Siyaloadenit & 20 & 36.8 & 44.5 \\
Siyalolitiyazis & 13 & 38.8 & 28.9 \\
BENiGN & & & \\
Pleomorfik Adenom & 4 & 22 & 8.9 \\
Lenfoepitelyal lezyon & 1 & 52 & 2.2 \\
& & & \\
MALiGN & & & \\
Adenokistik Karsinom & 1 & 32 & 2.2 \\
Lenfoma & 1 & 46 & 2.2 \\
& & & \\
Dí̆ER & & & \\
Ranula & 1 & 23 & 2.2 \\
Kazeifiye Granülomatöz & 4 & 37 & 8.9 \\
\hline
\end{tabular}

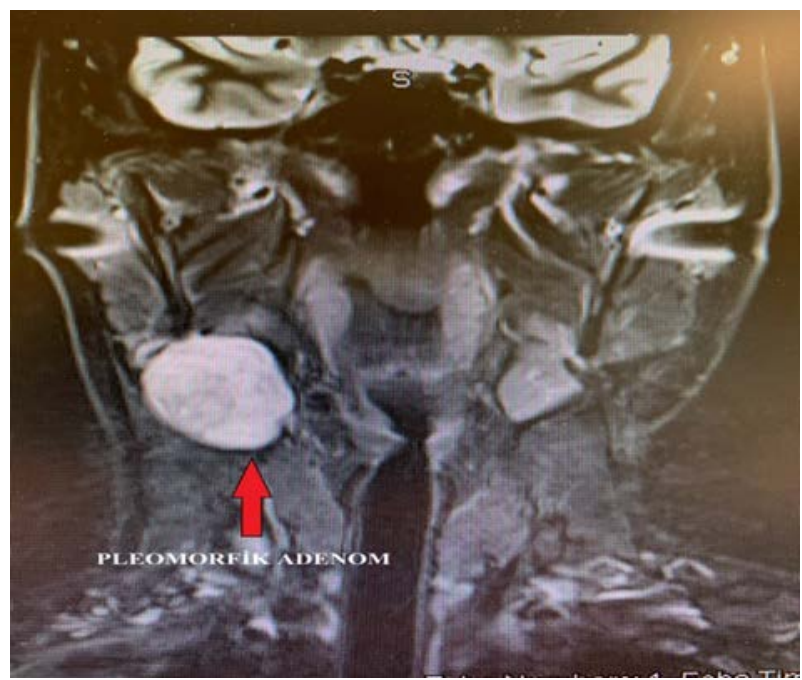

Şekil 1. Sağ pleomorfik adenom MR görüntüsü

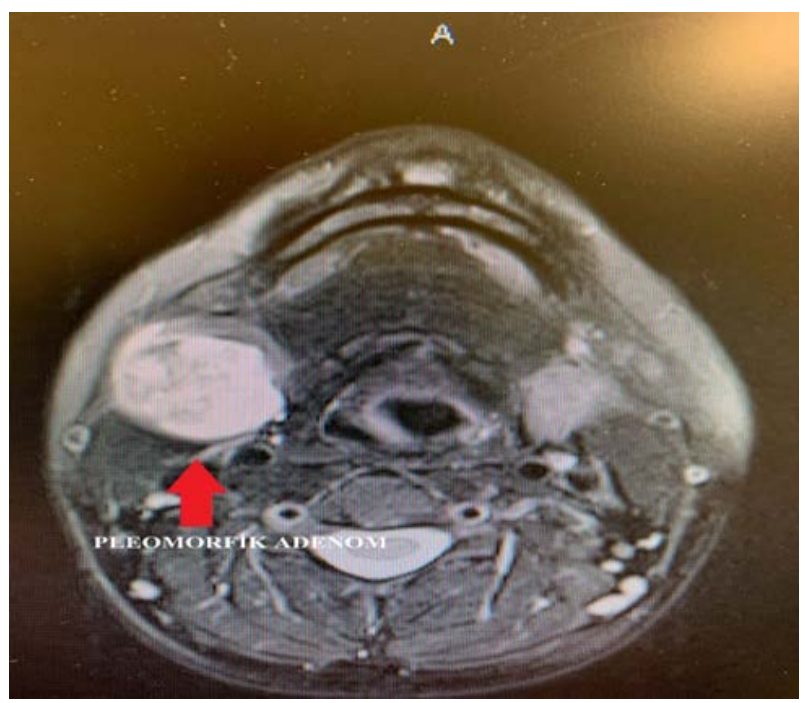

Şekil 2. Sağ pleomorfik adenom MR görüntüsü

Hastalardan 2'sinde (\%4.5) fasiyal sinir marjinal mandibular dalında geçici paralizi, bir hastada lingual sinirde geçici paralizi bir hastada ise operasyon sonrası yara yerinde enfeksiyon gelişmiştir. Paraliziler dört hafta içinde ilk on gün $1 \mathrm{mg} / \mathrm{kg}$ 'dan azaltılarak kesilen steroid tedavisi ile sekelsiz düzelmiştir. Yara yeri enfeksiyonu olan hasta yatırılarak parenteral antibiotik tedavisi ile sekelsiz düzelmiştir. Cerrahi sonrası enfeksiyon, taş veya rekürren kitleye bağlı revizyon cerrahiye ihtiyaç duyulmamıştır.

\section{Tartışma}

Submandibular bez cerrahilerinin büyük bir kısmı semptomatik hale gelen sialolitiyazis nedeniyle yapılmaktadır $(8,9)$. Submandibular bezde diğer majör tükürük bezlerinden daha fazla sıkıkta taş görülmesinin nedenleri; üretilen tükürük içeriğinin daha alkali yapısı, müsini daha fazla içermesi, bez kanalının daha uzun olması ve kalsiyum, fosfat içeriği bakımından daha zengin olmasından dolayıdır. Patogenezinde; dökülen epitelyum hücreleri, bakteriler ve tükürük müsinlerinden oluşan çekirdek etrafında kalsiyum tuzlarının birikimi neticesinde taşın oluştuğu kabul edilmektedir(10). Tükürük bezi taşları genellikle tek olup yaklaşık \%3-4 hastada iki veya daha fazla sayıda olabilmektedir. Submandibular bez taşları parotisin aksine daha çok kanal içi yerleşim gösterir $(11,12)$. Submandibular bezde taşlar her yaşta görülebilmesine karşın en sık 30-60 yaşlar arasında görülür(13). Hastalarımızda da en küçük görülme yaşı 10 , en büyük yaş 72 , ortalama yaş ise 36.2 olarak tespit edilmiştir.Siyalolithiasis genelikle erkeklerde daha sıktır, bizim çalışmamızda da 26 erkek(\%56.5) 19 kadın (\%41.3) hastada submandibular bez eksizyonuyla erkeklerin kadınlardan fazla olduğu görülmüştür(14).

Submandibüler bez patolojileri neoplastik ve neoplastik olmayan şeklinde iki grup halinde incelenebilir.Neoplastik submandibüler bez kitleleri tüm tükürük bezi tümörlerinin \%8-22'sini oluşturur. Bunların \%50-57'si benign geri kalanı malign tümörlerdir (15). Submandibular bez malign tümörlerinin sık görülmemesi geniş vaka serilerinin olmaması cerrahi ve cerrahi dışı tedaviler hakkında fikir birliği oluşmasını zorlaştırmaktadır.Çalışmamızda da literatürle uyumlu olarak en sık benign tümörler (\%11.1), bunlar içinde de en sık pleomorfik adenom 4 hasta, (\%8.9) tanı almışıı. Toplam malign tümör oranımız oldukça düşük olup (\%4.5), primer malign tümör olarak adeno kistik karsinom göze çarpmaktadır.Adeno kistik karsinom tanısı alan hastamız tedavisini başka merkezde sürdürmek isteyip takibimizden çıkmıştır.

Çocuklarda tükürük bezi tümörleri erişkinlerden çok daha düşük orandadır ,submandibular beze oranla parotis kitleleri çocuklarda 10 kat fazla görülür(16). Bu nedenle de pediatrik submandibuler bez tümörleri daha çok olgu sunumları şeklinde sporadik olarak bildirilmektedir. Bizim vaka serimizde beş çocuk yer almıştır. Bunlardan ikisi pleomorfik adenom birisi kronik sialoadenit,birisi sialolitiazis ve birisi de kazeifiye granülomatöz lezyon olarak rapor edildi.Çocuklardan en küçüğü 10 yaşında en büyüğü 16 yaşında idi. 
Submandibular taşların yaklaşık \%80'inin radyoopak olması nedeniyle tanıda direkt grafiler yardımcı olabilmektedir. Ön-arka pozisyonda ağız açık iken çekilen grafiler de taşların görülme intimali artmaktadır. Bu grafilerde görülen kalsifikasyonlar her ne kadar taş lehine yorumlansa da, ayrıcı tanıda tüberküloza bağı kalsifiye lenfadenopati, flebit, lingual arter aterosklerozu düşünülmelidir $(17,18)$. Submandibular bez taşlarının kesin tanısında sialografi ve Bilgisayarlı Tomografi(BT) kullanılabilir. Sialografi kullanılabilecek en temel yöntemken gerek kontrast alerjisi, gerekse yeterli teknisyen desteği alamadığımızdan kliniğimizde uygulanamamaktadır. Bilgisayarlı tomografi ise 23 hastada çekilmiş ve 22 hastada taş tesbit edilmiştir. Ama USG noninvaziv olması, maliyetinin az olması ve kolay ulaşılabilir olması nedeniyle taş tanısında kullanılan en yaygın yöntemdir(9,19). Submandibüler bez lezyonlarında USG önemli bir tanı aracıdır. Özellikle submandibüler bez yüzeyel lezyonlarında oldukça faydalıdır (6). Papaspyrou, siaIolitiazis tanısında USG'nin duyarlılık ve özgüllüğünü sırasıyla $\% 87$ ve $\% 81.3$ olarak rapor etmiştir(20). Bizim hasta serimizde de klinisyenlerin en sık tercih ettiği tetkik 29 hastada (\%64.4) oranıyla USG olmuştur ayrıca 23 hastada (\%51.1) BT, 18 hastada (\%40) MRG'ye ayırıcı tanı için ihtiyaç duyulmuştur.

Baş boyun kitleleri içinde, ince iğne aspirasyon biyopsisi (IIAB) literatürde en düşük sensitiviteyi submandibular bez kitlelerinde göstermiştir(21). Olubaniyi ve ark. bu bölge neoplastik patolojilerinde biyopsi metodlarını karşılaştırdığı bir çalışmasında ince iğne aspirasyon biyopsilerinde yaklaşık \%73 oranında tanı konulamadığııı rapor etmiştir(22). Ayrıca ince iğne biyopsi düşük dereceli lenfoma ve reaktif nodal hiperplazi ayrımında çoğu zaman yetersiz kalacağından birçok hastada eksizyonel biyopsi endikasyonu oluşturur(23). Görüntüleme yöntemlerinde taş tesbit edilemeyen ve radyolog tarafından histopatolojik korelasyon önerilen 11 hastada (\%24.4) IIIAB yapıldı. Hastalardan 10'unda benign sitoloji , bir hastada tanısal değil şeklinde raporlandı. IïAB sonucu benign sitoloji şeklinde raporlanan hastaların birinde submandibular gland eksizyonu sonrası patoloji raporu non-hodgkin lenfoma olarak geldi.

Trans servikal submandibüler bez cerrahileri sonrası geçici marjinal mandibüler sinir (MMS) hasarı literatürde \%36, kaIICI ise \%12 gibi yüksek oranlara kadar bildirilmektedir(24,25). Bizim hastalarımızın ikisinde postoperatif MMS paralizisi görüldü, hastaların 10 günlük tedavi sonrası 4 haftalık takipte spontan düzeldiği görüldü. Beze yönelik trans servikal cerrahi yaklaşımda MMS hasarı riskini azaltmaya yönelik subplatismal mandibula korpusundan yaklaşık iki parmak inferiordan yaklaşarak sinirin aranmadığı teknik kullanılmıştır.

Springborg ve ark. 139 hastalık serilerinde $\% 9.4$ oranında postoperatif enfeksiyon bildirmişlerdir(7). Bu komplikasyonu engellemek açısından preoperatif antibiyotik profilak- sisi kullandıklarını rapor etmişlerdir. Biz kliniğimizde preoperatif profilaksi kullanmamaktayız. Ancak postoperatif dönemde 10 gün profilaktik antibiyotik uygulamaktayız. Bizim serimizde bir vakada taburculuk sonrası yara yeri enfeksiyonu gelişti, hasta tekrar yatıılıarak tedavi edildi. Bir hastamızda da geçici lingual sinir paralizisi gelişti, takipte 4 hafta sonra hastanın şikayetleri düzeldi. Bir diğer komplikasyon post op hematomdur. Preuss ve ark.'nın yaptığı çalışmada post op hematom \%2 oranında görülmüştür(26). Bizim hastalarımızda post operatif hematoma rastlanmadı. Cerrahi komplikasyonlar arasında hipoglossal sinir hasarı oldukça nadir rapor edilmiştir (\%0-1.4) (7). Bu durum, sinirin bez alt 1/3'ünün inferomedialinde digastrik kas posterior karnı tarafından kısmen korunaklı bir bölgede yerleşmesinden kaynaklanır. Vakalarımızda hipoglossal sinir hasarına rastlanmadı.

Sonuç; Submandibuler bezde kitle şikayeti ile başvuran hastalarda tanı çoğunlukla kronik sialadenit ve sialolitiazis olmuştur. Trans servikal submandibuler bez eksizyonu,cerrahi tekniklere uyulduğunda ve seçilmiş hastalara uygulandığında,düşük komplikasyon ve nüks oranlarıyla yüz güldürücüdür. Hasta sayımızın yüksek rakamlara ulaşmaması, hastalarımızın bir kısmının tedavisini başka merkezde sürdürme isteği post-op takiplerimizi aksatması çaıışmamızın limitasyonlarıdır. Cerrahi sahaya yakın sinirlerde oluşabilecek hasar sonucu gelişecek nörolojik komplikasyonlardan cerrahi kurallara uygun yaklaşım ve dokulara saygılı yaklaşım ile kaçınılabilir.

Etik Onam: Çalışma için Harran Üniversitesi Tıp Fakültesi Etik Kurulu'ndan etik kurul onayı alındı (28/08/2019E.35566 tarih ve sayılı karar).

\section{Kaynaklar}

1. Açıkalın RM, Özbay İ, Veyseller B, et al. Submandibular Bez Eksizyonu: 43 Olgunun Analizi. Haseki Tıp Bülteni 2014;52(3):199-201. doi: 10.4274/haseki.1374

2. Dalgic $A$, Karakoc $O$, Karahatay $S$, et al. Submandibular triangle masses. The Journal of craniofacial surgery 2013;24(5):e529-31. doi: 10.1097/SCS.0b013e3182a238f9

3. Ellies M, Gottstein U, Rohrbach-Volland S, Arglebe C, Laskawi R. Reduction of salivary flow with botulinum toxin: extended report on 33 patients with drooling, salivary fistulas, and sialadenitis. The Laryngoscope 2004;114(10):1856-60.

4. Erbek SS, Koycu A, Topal O, Erbek HS, Ozluoglu LN. Submandibular Gland Surgery: Our Clinical Experience. Turkish archives of otorhinolaryngology 2016;54(1):16-20. doi: 10.5152/tao.2016.1467

5. Harrison J, Epivatianos A, Bhatia S. Role of microliths in the aetiology of chronic submandibular sialadenitis: a clinicopathological investigation of 154 cases. Histopathology 1997;31(3):237-51.

6. Lee $Y Y$, Wong KT, King AD, Ahuja AT. Imaging of salivary gland tumours. European journal of radiology 2008;66(3):419-36. doi: 10.1016/j.ejrad.2008.01.027

7. Springborg LK, Moller MN. Submandibular gland excision: long-term clinical outcome in 139 patients operated in a single institution. European archives of oto-rhino-laryngology : official journal of the European Federation of Oto-Rhino-Laryngological Societies 2013;270(4):1441-6. doi: 10.1007/s00405-012-2175-48.

8. Bodner L, Azaz B. Submandibular sialolithiasis in children. J Oral 
Maxillofac Surg 1982;40(9):55I-4.

9. Berçin S, Kutluhan A, Yurttaş V, Kanmaz A. Submandibuler sialolityazise yaklaşımımız. Yeni Tıp Dergisi 2009;26: 16-19.

10. Siddiqui SJ. Sialolithiasis: an unusually large submandibular salivary stone. Br Dent J 2002;193:89-91.

11. Perrotta RJ, Williams JR, Selfe RW: Simultaneous bilateral parotid and submandibular gland calculi. Arch Otolaryngol Head Neck Surg 1978;104(8):469-70.

12. Lustmann J, Regev E, Melamed Y. Sialolithiasis: A survey on 245 patients and a review of the literature Int $\mathrm{J}$ Oral Maxillofacial Surg 1990;19 (3):135-8.

13. Isacsson $G$, Isberg $A$, Haverling $M$, Lundquist PG. Salivary calculi and chronic sialoadenitis of the submandibular gland: A radiographic and histologic study. Oral Surg 1984;58(5): 622-7.

14. Work WP, Hecht DW. Inflammatory diseases of the majorsalivary glands In: Papparella MM, Shumrick DF, editors.Otolaryngology Philadelphia. WB Saunders; 1980; p. 2235- 43.

15. Spiro RH. Salivary neoplasms: overview of a 35-year experience with 2807 patients. Head Neck Surg 1986; 8: 177-84.

16. Bentz BG, Hughes CA, Lüdemann JP, Maddalozzo J. Masses of the salivary gland region in children. Arch Otolaryngol Head Neck Surg 2000; 126: 1435-9.

17. Paul D, Chaulan SR. Salivary megalith with a sialo-cutaneous and a sialo-oral fistula: A case report. J Laryngol Otol 1995;109(8):767-9.

18. Rice DH. Diseases of the salivary glands non-neoplastic. In: Bailey BJ, Johnson JT, Kohut RI, eds. Head and Neck Surgery-Otolaryngology. Vol 1. Philadelphia: JB, Lippincott; 1993. p. 475-84.

19. Lustmann J, Regev E, Melamed Y. Sialolithiasis: A survey on 245 patients and a review of the literature Int $\mathrm{J}$ Oral Maxillofacial Surg 1990;19 (3):135-8.

20. Papaspyrou G, Werner JA, Sesterhenn AM. Transcervical extirpationof the submandibular gland: the University of Marburgexperience. Eur Arch Otorhinolaryngol 2014; 271: 2009-12

21. Yılmaz İ, Çağıcı C A, Çaylaklı F, Akdoğan V, Özlüoğlu L N. BaşBoyun kitlelerinde İnce iğne aspirasyon biyopsisinin yeri. Kulak Burun Boğaz Ihtisas Dergisi 2008;18(4):211-15.

22. Olubaniyi BO, Chow V, Mandalia U, Haldar S, Gok G, Michl P,et al. Evaluation of biopsy methods in the diagnosis of submandibularspace pathology. Int J Oral Maxillofac Surg 2014; 43: 281-5.

23. Sellon E, Moody A, Howlett D. Ultrasound guided core biopsyis the diagnostic tool of choice in salivary gland swellings. BMJ 2012; 345: e7782.

24. Smith WP, Peters WJ, Markus AF. Submandibular gland surgery:an audit of clinical findings, pathology and postoperative morbidity. Ann R Coll Surg Eng 1993; 75: 164-7.

25. De M, Kumar Singh P, Johnson AP. Morbidity associated withsubmandibular gland excision: a retrospective analysis. Internat $\mathrm{JHead}$ Neck Surg 2006; 1: 1

26. Preuss SF, Klussmann JP, Wittekindt C, Drebber U, Beutner D, Guntinas-Lichius O. Submandibular gland excision: 15 years of experience. J Oral Maxillofac Surg 2007;65:953-7. 